Article

\title{
The Preparation and Characterization of a Cyanide-Free Brush-Plating Solution for Application in the Electric Power Industry
}

\author{
Kewang Zheng ${ }^{1,2}$, Zhifei Meng ${ }^{1}$, Jingxian Li ${ }^{1}$, Shuai Peng ${ }^{1}$, Chaofan Huang ${ }^{1}$, Wei Wang ${ }^{1, *}$, Wei Li $^{1, *}$ and \\ Caiqin Qin 1,2 (D)
}

check for

updates

Citation: Zheng, K.; Meng, Z.; Li, J.; Peng, S.; Huang, C.; Wang, W.; Li, W.; Qin, C. The Preparation and Characterization of a Cyanide-Free Brush-Plating Solution for Application in the Electric Power Industry. Coatings 2022, 12, 194. https://doi.org/10.3390/coatings 12020194

Academic Editor: Véronique Vitry

Received: 28 December 2021

Accepted: 31 January 2022

Published: 2 February 2022

Publisher's Note: MDPI stays neutral with regard to jurisdictional claims in published maps and institutional affiliations.

Copyright: (C) 2022 by the authors. Licensee MDPI, Basel, Switzerland. This article is an open access article distributed under the terms and conditions of the Creative Commons Attribution (CC BY) license (https:// creativecommons.org/licenses/by/ $4.0 /$ )
1 School of Chemistry and Materials Science, Hubei Engineering University, Xiaogan 432000, China; kewang@hbeu.edu.cn (K.Z.); meng16301@163.com (Z.M.); hbeuljx@163.com (J.L.); shuaip0102@126.com (S.P.); chaofan0502@126.com (C.H.); qincq@hbeu.edu.cn (C.Q.)

2 Key Laboratory of Biological Resources and Environmental Biotechnology, Wuhan University, Wuhan 430000, China

* Correspondence: weiwang@hbeu.edu.cn (W.W.); weili@hbeu.edu.cn (W.L.)

\begin{abstract}
In this paper, a bright and compact silver coating on a copper sheet was successfully prepared by a coating solution without cyanogen. The effects of cerium nitrate $\left(\mathrm{Ce}\left(\mathrm{NO}_{3}\right)_{3}\right)$ content on the structures, physicochemical properties, and application of the coating were thoroughly discussed with the help of scanning electron microscopy (SEM), energy-dispersive X-ray spectroscopy (EDS), mapping, X-ray diffraction (XRD) electrochemical workstation, and infrared thermometer. The results pointed out that the thickness of the silver coating could reach about $30 \mu \mathrm{m}$, with good adhesion to the copper substrate. Cerium nitrate was evenly distributed on the surface of the coating, which can effectively refine the crystal grains and enhance the corrosion resistance. When the dosage of cerium nitrate was $1.0 \mathrm{~g} / \mathrm{L}$, the crystal grains were decreased from $144 \mathrm{~nm}$ to $65 \mathrm{~nm}$, and the corrosion voltage was increased from $-0.238 \mathrm{~V}$ to $-0.131 \mathrm{~V}$, respectively. The silver plating layer showed the best corrosion resistance with the dosage of silver nitrate, sulfosalicylic acid, additive, cerium nitrate, ammonium acetate, polyethylene glycol 400, and the number of brush-plating operations were 10, $50,55,1,10,10 \mathrm{~g} / \mathrm{L}$, and 8 times, respectively. For application, the temperature of the transformer's isolating switch could remarkably be decreased from $100{ }^{\circ} \mathrm{C}$ to $54{ }^{\circ} \mathrm{C}$ with brushing plating by the silver coating solution.
\end{abstract}

Keywords: brush plating; silver plating; performance testing; application

\section{Introduction}

Copper $(\mathrm{Cu})$ has been widely used in the electric power industry due to its high electrical and thermal conductivities, adequate strength, and low cost [1-3]. However, equipment made by copper is easily oxidized in the natural environment, and the copper oxide film is not as dense as an aluminum oxide film, to form a protective effect on itself. Furthermore, the oxide film of copper directly affects its own electrochemical performance, such as electrical and thermal conductivity. Due to the high resistance of the oxide film, considerable amounts of power loss and heat are generated at the isolating switch and other joint equipment, which further oxidize the copper equipment, thus causing power breakdowns. According to statistics, about $20 \%$ of power equipment failures are caused by overheating of the contact such as the guide joint and terminal post of the equipment, and almost $80 \%$ of power failures are caused by overheating of the contact during the peak period of power consumption. In order to avoid this, some strategies were applied to protect power equipment joints from corrosion or damage, such as electric brush-plating and electrochemical deposition methods [4-6]. The electric brush-plating technique, in which equipment surfaces are coated with a coating layer by a coating solution, was widely 
applied in the surface protecting and machine-building industries [7]. Due to its advantages of low cost, easy movability, high deposition rate, and simple device, it was widely used in repairing isolating switches and other joint equipment.

In the industry, it is common practice to coat metals with silver to ensure a more stable, less oxidized contact surface and lower inherent joint resistance [8]. Güler et al. prepared a new copper-based electrical contact material based on copper substrate and silver nickel-alloy coating, and results showed that the wear and arc-erosion performances of the materials could be up to 10 times greater than the pure copper [9]. However, traditional silver plating solution usually contains other heavy metals (such as chromium, lead, etc.) and cyanogenic compounds, leading to toxic gases and wastewater that may be released during the brush-plating process, which would cause great harm to people's health and the environment. Therefore, researchers made some efforts to improve the silver brush-plating solution, such as adding some rare-earth elements. Montemor et al. obtained bis-aminosilane coating on AZ31 magnesium alloy by brushing plating, and the results revealed that the corrosion rate of the Mg AZ31 substrates was significantly slowed with the addition of the rare-earth salt [10]. Zhang et al. analyzed the effect of rare-earth content on the properties of nickel plating and nickel-cobalt alloy, and the results showed that rare-earth elements could reduce the porosity and crack density of the coating and could also make the coating grain more uniform [11]. Yang et al. prepared the double rareearth-modified coating film by using rare-earth lanthanum and cerium on the surface of magnesium alloy [12]. The results showed that the surface cracks of the coating significantly reduced and the corrosion resistance, and oxidation resistance improved.

Cerium is the most abundant rare-earth element in the earth's crust. Due to its excellent chemical properties, cerium-based oxides have widely been used in many advanced function materials, such as catalysis, corrosion prevention, electrochemical cells, metal plating, biomaterials, etc. Rare-earth elements are used as special additives in the electroplating solution, which can obviously improve the properties of coating layers [13-18]. However, there are few reports on the effect of silver brush-plating solution with cerium-based oxides for repairing isolating switches or other joint equipment.

Therefore, in this study, an environmentally friendly coating silver brush-plating solution based on silver nitrate and sulfosalicylic acid was obtained, and the physicochemical properties and application effect of the silver coating layer were also characterized. We believe that the proposed system based on the environmentally friendly silver-coating solution can widely be used in the power industry.

\section{Experimental}

\subsection{Plating Composition}

Preparation of the additive: imidazole, N, N-dimethylformamide, and hexamethylenetetramine were mixed by the weight of 100:1:1.

The silver brush-plating solution was made by adding the above drugs listed in Table 1 into a beaker and stirring at room temperature with a homogenizer for at least $20 \mathrm{~min}$. Afterward, the $\mathrm{pH}$ of the solution was adjusted to weakly alkaline $(\mathrm{pH}=8-9)$ by ammonium hydroxide and nitric acid. The preparation process was shown in Figure 1.

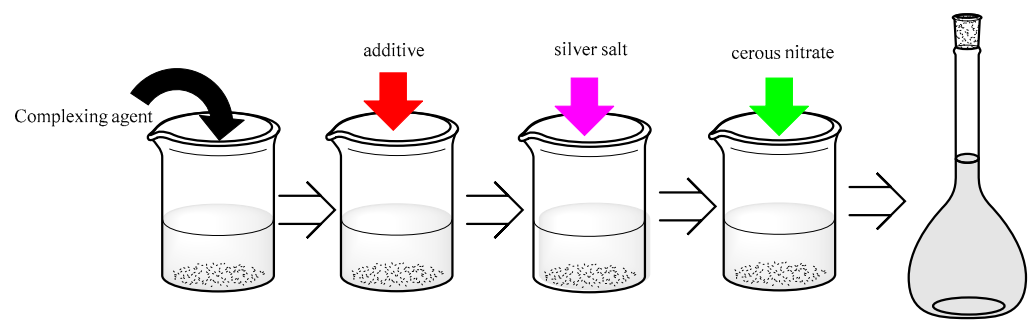

Figure 1. Brief description of the manufacture of silver brush-plating solution. 
Table 1. Composition of silver plating solution reagent.

\begin{tabular}{ccccccc}
\hline \multirow{2}{*}{ Ingredient } & Main Salt (g/L) & $\begin{array}{c}\text { Complex } \\
\text { Agent }(g / L)\end{array}$ & Additive (g/L) & $\begin{array}{c}\text { Rare Earth } \\
(\mathrm{g} / \mathrm{L})\end{array}$ & $\begin{array}{c}\text { Buffer Agent } \\
(\mathrm{g} / \mathrm{L})\end{array}$ & $\begin{array}{c}\text { Surface Active } \\
\text { Agent }(\mathrm{g} / \mathrm{L})\end{array}$ \\
\cline { 2 - 7 } & Silver Nitrate & $\begin{array}{c}\text { Sulfosalicylic } \\
\text { Acid }\end{array}$ & Hybrid & Cerium Nitrate & $\begin{array}{c}\text { Ammonium } \\
\text { Acetate }\end{array}$ & $\begin{array}{c}\text { Polyethylene } \\
\text { Glycol 400 }\end{array}$ \\
\hline Content range & $10-30$ & $50-90$ & $50-70$ & $0.5-1.5$ & $10-20$ & $10-20$ \\
Specific content & 10 & 50 & 55 & $0.5-1.5$ & 10 & 10 \\
\hline
\end{tabular}

\subsection{Copper Sheet Pretreatment}

Preparation of the alkaline electrolyte: a total of $20 \mathrm{~g}$ sodium hydroxide, $20 \mathrm{~g}$ sodium carbonate, $70 \mathrm{~g}$ trisodium phosphate dodecahydrate, and $2 \mathrm{~g}$ sodium chloride were added in deionized water, to make $1000 \mathrm{~mL}$ of solution.

Preparation of the citric acid type activation liquid: a total of $130 \mathrm{~g}$ sodium citrate dihydrate, $90 \mathrm{~g}$ citric acid monohydrate, and $2 \mathrm{~g}$ nickel chloride hexahydrate were added in deionized water, to make $1000 \mathrm{~mL}$; then, the $\mathrm{pH}$ of it was adjusted to $3.5-4$ by hydrochloric acid.

The substrate was made of copper having a purity of $99.97 \%$ and a size of $50 \mathrm{~mm}$ $\times 20 \mathrm{~mm} \times 0.2 \mathrm{~mm}$. The bare copper was first deoxidized by polishing in one direction with 2000 mesh sandpaper 10 times, to obtain a copper sheet that was bright and flat on the macroscopic surface. Then, the oil removal treatment was carried out with an alkaline electrolyte, and the electrolytic copper plate was activated by a citric acid-type activation liquid. The treated copper sheet was rinsed with deionized water, blown dry, and then immersed in alcohol for use.

\subsection{Experimental Process and Post-Processing}

An electroplating pen was used as the anode, and the copperplate to be brushed was connected to the cathode. The voltage range during brush plating was set to 0.5-2.0 V. After brush plating, the residual brush-plating solution on the surface of the coating was rinsed with deionized water and dried quickly.

\subsection{Scanning Electron Microscopy}

Silver plating was photographed at different magnifications using a scanning electron microscope (SEM, 300VP, Zeiss, Jena, Germany). The surface of the coating was microscopically enlarged to observe the microscopic surface morphology of the silver coating and determine whether there were obvious defects, uneven grain distribution, peeling of the coating from the substrate, or foaming. The section of the coating was mainly to observe the connection between the coating and the substrate and the thickness of the coating. By microscopic enlargement, the state of the junction of the two phases was observed, and the approximate thickness of the silver coating was measured by the dimensioning of the scanning electron microscope.

\subsection{Characterization of Coating Adhesion}

Two methods outlined in the QB/T 3821-1999 Light Industry Standards of the People's Republic of China were used to evaluate the coating adhesion strength. The first method uses a hard steel knife to draw scratches every $1 \mathrm{~mm}$ along the horizontal and vertical directions on the coating surface. These scribe lines divide the surface of the base copper sheet into $1 \mathrm{~mm}$ grid squares. Whether the coating flaked off the substrate differentiated good and bad adhesion.

Another method was selected in which a copper is coated with silver coating, and the copper substrate is then bent back and forth repeatedly until the copper piece breaks while observing the fracture and judging the adhesion of the coating by whether the plating layer and the substrate fall off or separate. 
The copper sheets subjected to the scratch test were heat treated at 20,30,50, 70, 90 and $110{ }^{\circ} \mathrm{C}$, for $2 \mathrm{~h}$ and under the same conditions. Then, the scratched portion was enlarged by a polarizing microscope, the connection between the silver plating layer and the substrate at the scratch was observed, and the influence of temperature on the adhesion property of the silver plating layer was compared.

\subsection{Electrochemical Experiment}

The electrochemical properties of the coating were analyzed by a three-electrode system [19]. The silver coating layer, saturated calomel electrode (SCE), and platinum wire were used as working electrode, reference electrode, and counter electrode, respectively. A 3.5\% sodium chloride solution was adjusted to $\mathrm{pH} 5$ and used as the electrolyte in this system. The back side of the brush-plating layer was coated with a resin before conducting the electrochemical experiment. At room temperature, the working electrode was placed in the electrolyte, to measure the open circuit potential for $30 \mathrm{~min}$, and the polarization curve of the sample was measured after the working electrode stabilized. The scanning interval was $\pm 400 \mathrm{mV}$ relative to the open circuit potential, and the scanning rate was 1 $\mathrm{mV} / \mathrm{s}$. Each sample was tested three times, and the corrosion current and corrosion voltage of the sample were obtained from the average value of the test.

\subsection{Metal Element Distribution}

The elements on the surface of the coating and their distribution were investigated by energy-dispersive X-ray spectrometers (EDX, 300VP, Zeiss, Jena, Germany). and elemental mappings. The crystal of the coating layer was tested by XRD (D8 advance, Karlsruhe, Germany).

\subsection{Application Measurement}

Firstly, an isolating switch of large-scale power equipment was repaired with the silver coating solution, and then, the power equipment was normally run for 2 days, after which the temperature of the repaired isolating switch was tested by an infrared thermal imager (GD-E4, Guodian west high, Wuhan, China). The temperature of the unrepaired isolating switch was also tested by the same conditions.

\section{Results and Discussion}

The defects and flatness of the microstructure and the grain size and arrangement of the metal particles can preliminarily reflect the basic performance characteristics of the coating. Figure 2 shows the surface and section morphologies, when the coating based on the dosage of silver nitrate, sulfosalicylic acid, additive, cerium nitrate, ammonium acetate, polyethylene glycol 400, and the number of brush-plating operations were 10, 50, 55, 1, 10 and $10 \mathrm{~g} / \mathrm{L}$, and 8 times, respectively.

As shown in Figure 2a,b, the low magnification map showed that the microstructures of the silver plating layers with or without adding cerium nitrate were rough, continuous, and still had obvious scratches, but the silver-plating layer with added cerium nitrate was obviously smoother than that without cerium nitrate. It can be seen that as the magnification increased, the microstructures of the plating layers were obviously changed. The silver-plated crystals on the surface of the plating layers with added cerium nitrate were denser and more ordered, with smaller size crystals, and had fewer defects on the surface than those without cerium nitrate. When the dosage of cerium nitrate was $1.0 \mathrm{~g} / \mathrm{L}$, the crystal grains were decreased from $144 \mathrm{~nm}$ to $65 \mathrm{~nm}$ [20]. Wang et al. observed a similar phenomenon; they obtained nickel-based alloy power with different content of $\mathrm{CeO}_{2}$ or $\mathrm{La}_{2} \mathrm{O}_{3}$, and their results showed that additions of rare-earth oxide $\mathrm{CeO}_{2}$ or $\mathrm{La}_{2} \mathrm{O}_{3}$ could refine and purify the microstructure of coatings and reduce the dilution of clad material from the substrate [21]. 


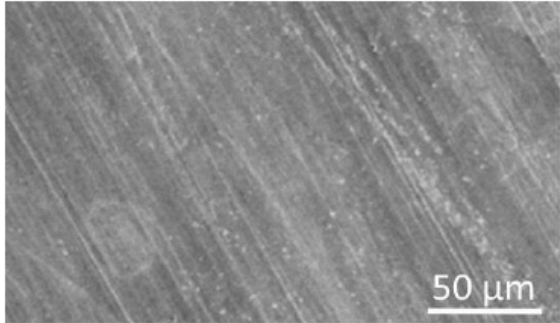

(a)

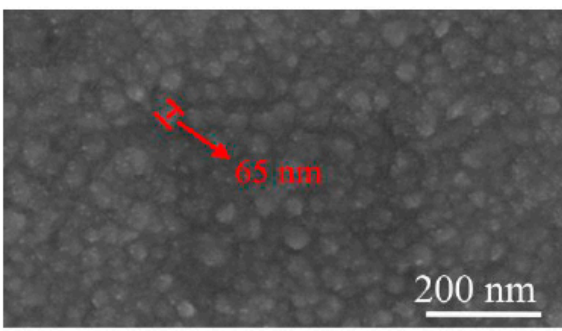

(c)

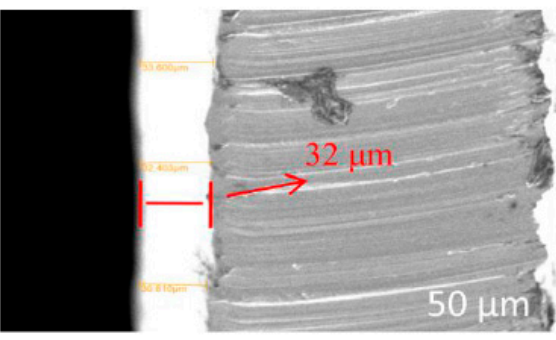

(e)

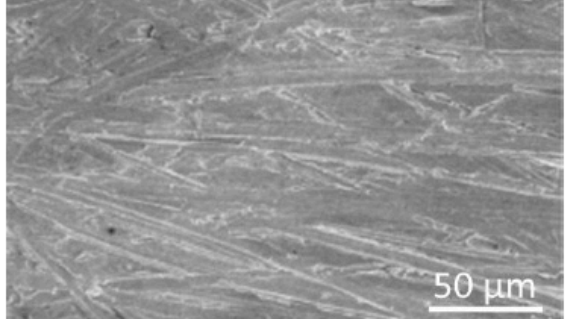

(b)

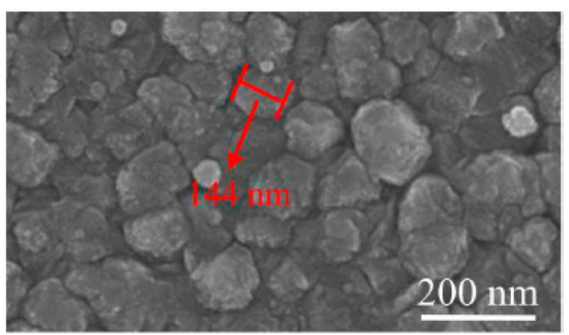

(d)

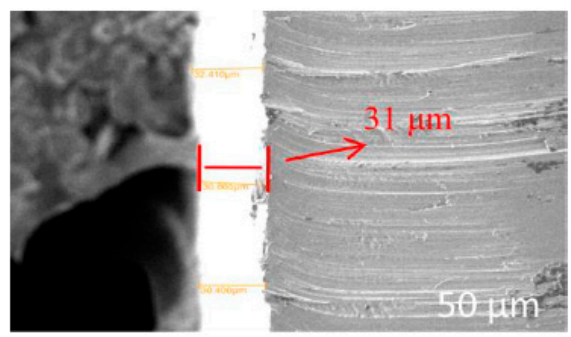

(f)

Figure 2. Surface morphologies of silver coating prepared: (a,c,e) containing $1.0 \mathrm{~g} / \mathrm{L}$ cerium nitrate; $(\mathbf{b}, \mathbf{d}, \mathbf{f})$ not containing cerium nitrate.

This phenomenon indicated that the addition of cerium nitrate could make the grain size more uniform and finer, reduce the porosity of the coating and the crack density of the silver layer, and make the grains more orderly. The same phenomenon was found by Zhang et al., who added rare-earth elements $\left(\mathrm{Sc}_{2} \mathrm{O}_{3}, \mathrm{Y}_{2} \mathrm{O}_{3}\right.$, and $\left.\mathrm{La}_{2} \mathrm{O}_{3}\right)$ to aluminum matrix composite coatings [22]. From the images of the cross-section of the coating, the silver coating and the copper substrate all had an obvious, homogenous, and tight interface with or without cerium nitrate, and the thicknesses of the coating were all over $30 \mu \mathrm{m}$, which could meet the needs of the power industry.

Figure 3 shows a microscopically enlarged view of the silver-plating layer's scratch test with treatment at different temperature conditions. It was found that all coating surfaces at different temperatures did not have foaming or detachment from the substrate. In addition, there were no defects or debris on the scratch. The results showed that the coating has good adhesion on the glistening surface of the substrate at the temperature range of $20-110^{\circ} \mathrm{C}$. 


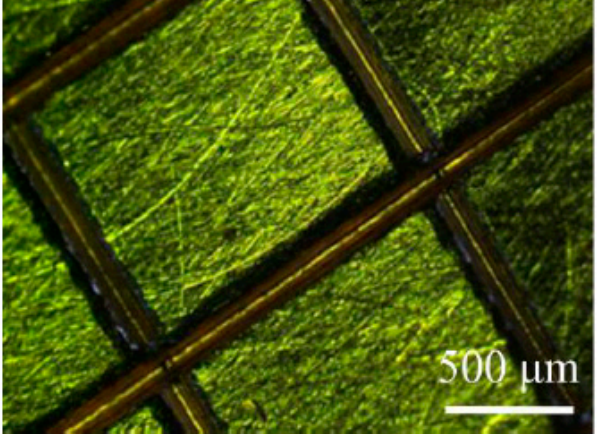

(a)

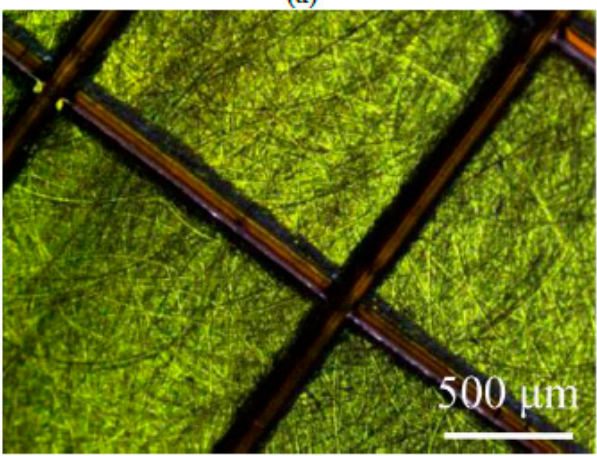

(c)

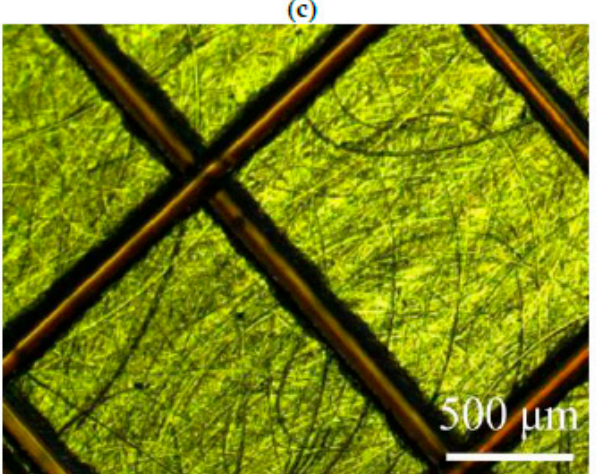

(e)

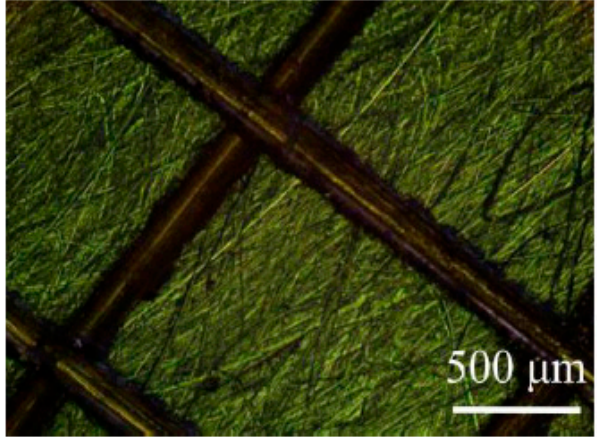

(b)

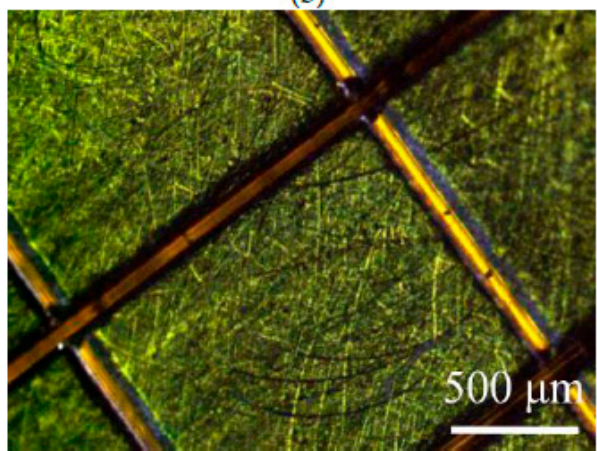

(d)

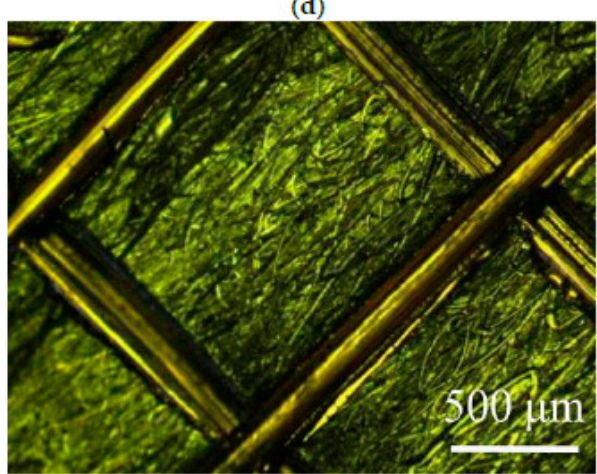

(f)

Figure 3. Microscopic enlargement of the scratch test: (a) $20^{\circ} \mathrm{C}$, (b) $30^{\circ} \mathrm{C}$, (c) $50{ }^{\circ} \mathrm{C}$, (d) $70{ }^{\circ} \mathrm{C}$ (e) $90^{\circ} \mathrm{C}$, and (f) $110^{\circ} \mathrm{C}$.

In Figure 4a,c,e are corrosion micrographs of the silver coating that contained $1.0 \mathrm{~g} / \mathrm{L}$ cerium nitrate. Figure $4 b, d, f$ are microscopic images of cerium nitrate-free coatings. It can be seen from these images that after 1-day immersion, a slight amount of yellow rust spots began to appear on the surface of the coating that contained cerium nitrate, but the rust spots of the cerium nitrate-free coating were more obvious. After 5 days, there were some scattered rust spots on the surface of the coating that contained cerium nitrate-free coating, and the silver layer was disappeared (Figure 4d). After 10 days of immersion, the surface of the silver coating that contained cerium nitrate was basically corroded, but the copper substrate of the control group underwent serious corrosion. The results showed that the corrosion of the coating in brine is a slow process, and the addition of cerium nitrate to the system can slow the corrosion rate of the coating to some extent. 


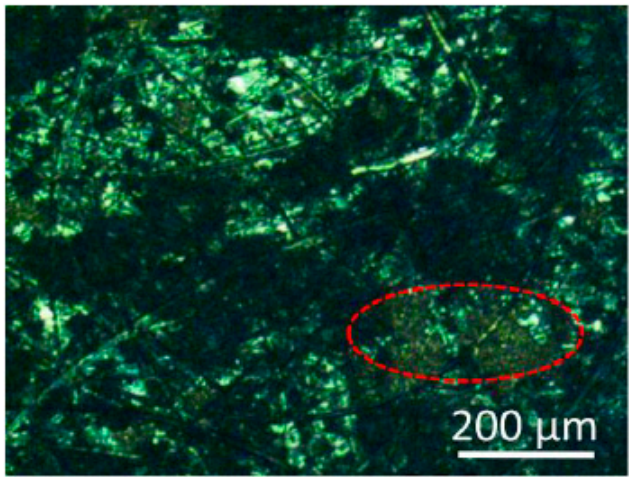

(a)

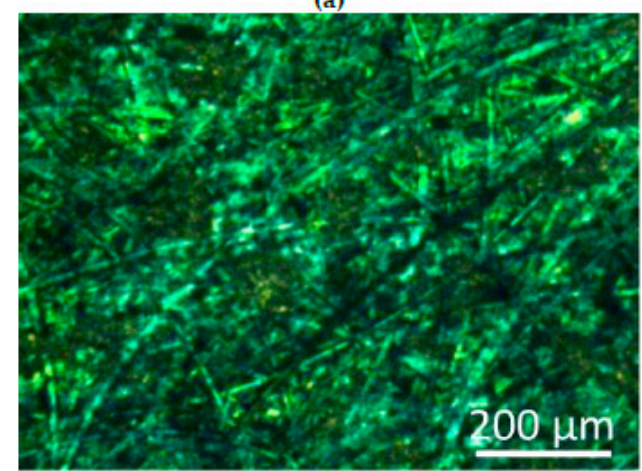

(c)

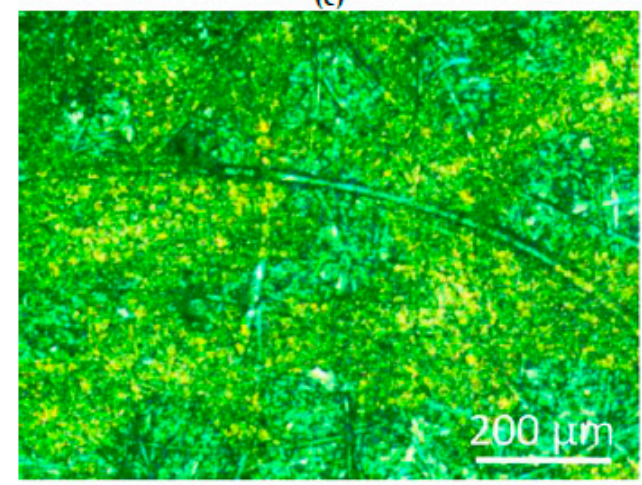

(e)

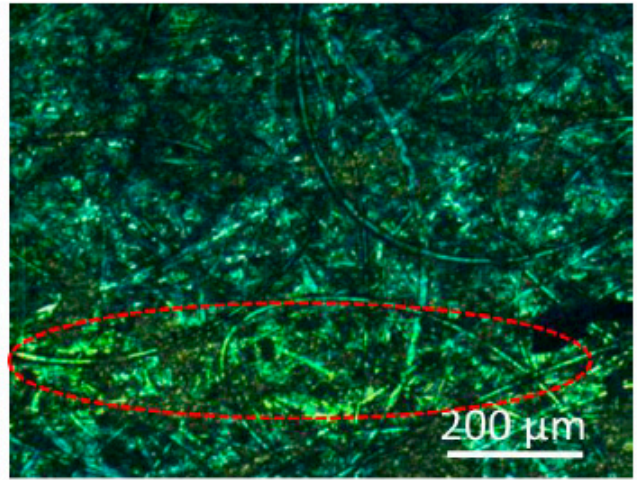

(b)

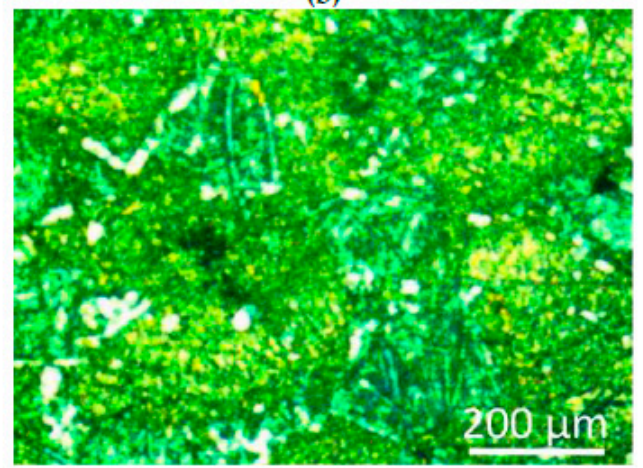

(d)

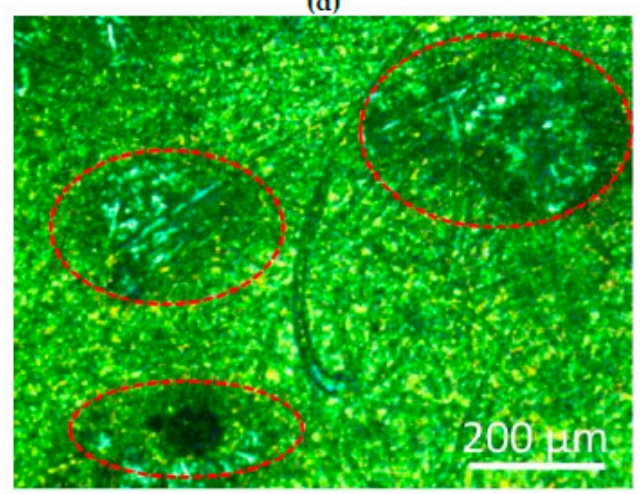

(f)

Figure 4. Pictures of corrosion test at different time: (a) and (b) for 1 day; (c) and (d) for 5 days; (e) and (f) for 10 days.

In order to compare the influence of various factors in the plating solution on the corrosion resistance of the coating, a Tafel polarization curve test was carried out for different rare-earth contents, brush-plating times, additive dosages, and complexing agent dosages, as shown in Figure 5. The higher the self-corrosion voltage, and the smaller the self-corrosion current, the better the corrosion resistance of the coating, and the slower the corrosion rate. It could be clearly seen that the slopes of the Tafel curve were approximately the same. The corrosion current and corrosion voltage of the coating layer were changed by different conditions [23]. When cerium nitrate was added to the coating solution, the corrosion voltage of the coating layer was first increased and then decreased, reaching the maximum value of the coating when the dosage of cerium nitrate was $1.0 \mathrm{~g} / \mathrm{L}$, which indicated that this dosage was best. When different amounts of additive content were incorporated, the corrosion voltage of the coating was also first increased and then decreased, and reached the maximum value when the additive was $50 \mathrm{~g} / \mathrm{L}$. The corrosion voltage of the coating layer reached the maximum value when the content of the complexing agent was $50 \mathrm{~g} / \mathrm{L}$, while at the same time, the corrosion currents of the layer were slightly changed, which indicated that the best content of the complexing agent was $50 \mathrm{~g} / \mathrm{L}$ based 
on these data. As for the number of brush plating, it was found that the corrosion voltage of the coating layer was gradually increased with the brush-plating times, but when the brush-plating times increased from 8 to 12 , the corrosion current and corrosion voltage of the coating layer had minimally changed. In order to save costs, the best brush-plating time was chosen as 8 .

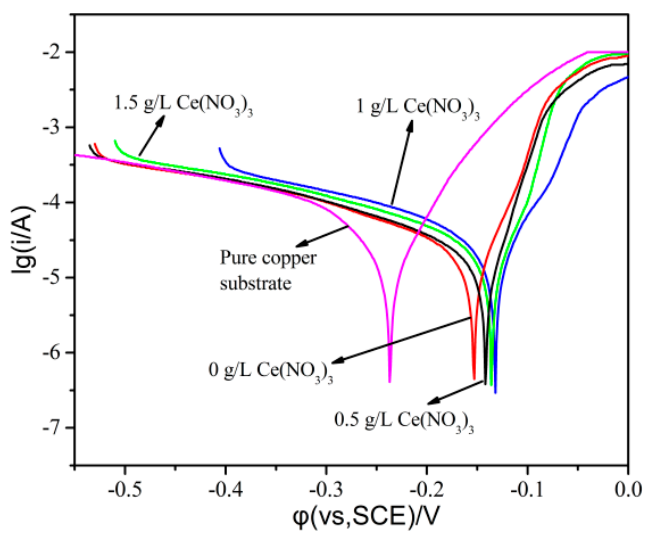

(a)

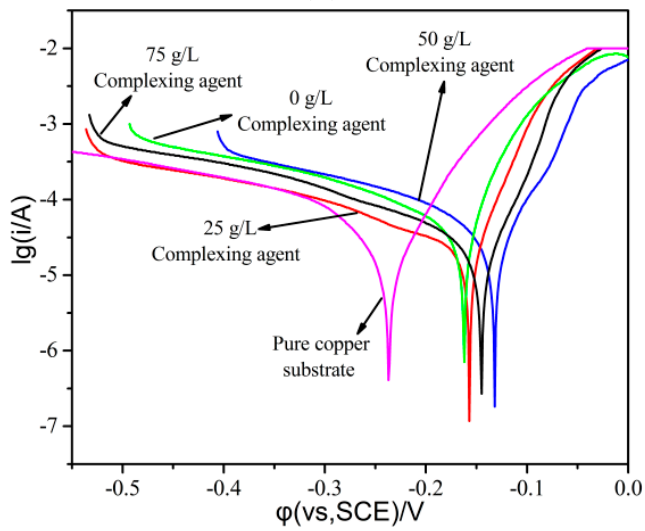

(c)

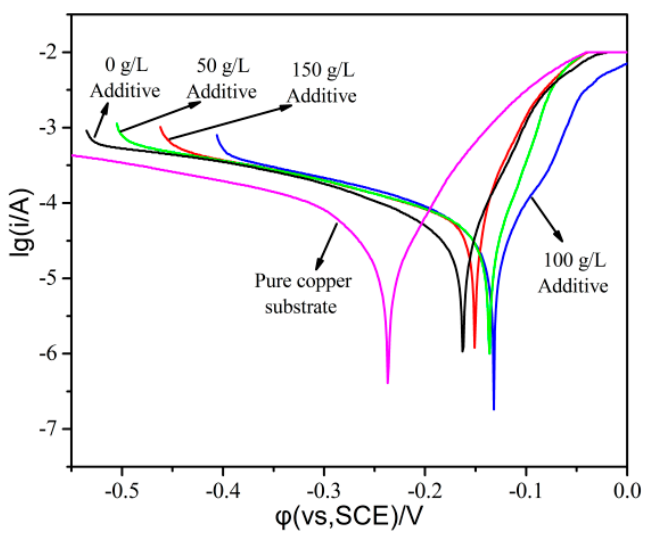

(b)

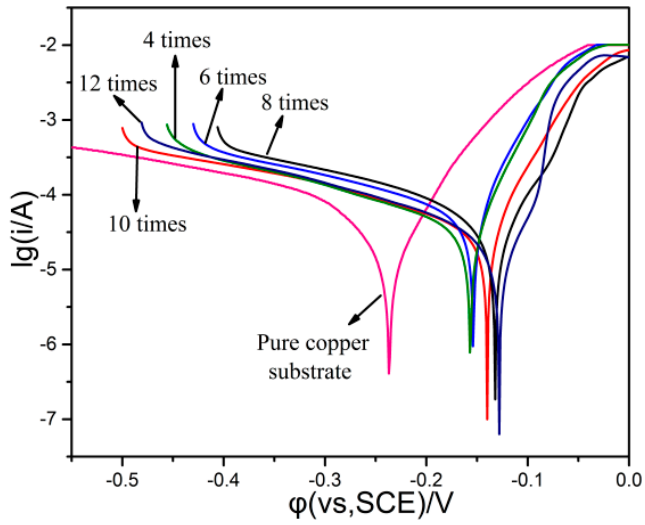

(d)

Figure 5. Plating electrochemical workstation Tafel polarization curve: (a) different amounts of cerium nitrate content; (b) different amounts of additive content; (c) different amounts of complexing agent content; (d) different brush-plating times.

The electrochemical parameters of the polarization curve were numerically fitted. The results are shown in Table 2. It can be seen from Table 2 that with the increase in cerium nitrate content, additive content, complexing agent content, and brush-plating times, the self-corrosion potential ( $\mathrm{E}_{\mathrm{corr}}$ ) of the coating first increased and then decreased, and the self-corrosion potential ( $\left.\mathrm{E}_{\mathrm{corrr}}\right)$ of the coating increased with the number of brush plating. The self-corrosion current $\left(\mathrm{I}_{\text {corr }}\right)$ had a poor regularity, but the self-corrosion current at the maximum of the self-corrosion potential was basically at a low level $[24,25]$. The results showed that the preferred values of silver nitrate content, sulfosalicylic acid content, additive content, cerium nitrate content, ammonium acetate content, polyethylene glycol 400 content, and the number of brush-plating operations were 10, 50, 55, 1, 10 and $10 \mathrm{~g} / \mathrm{L}$, and 8 times, respectively. 
Table 2. Corrosion current and corrosion voltage of silver plating under different influencing factors.

\begin{tabular}{ccc}
\hline Influencing Factors & $\mathbf{I}_{\text {corr }}\left(\times \mathbf{1 0}^{-\mathbf{6}} \mathbf{A} \cdot \mathbf{c m}^{-\mathbf{2}}\right)$ & $\mathbf{E}_{\text {corr }} \mathbf{( V )}$ \\
\hline Pure Copper & $1.413 \pm 0.151$ & $-0.238 \pm 0.021$ \\
Complexing agent $0 \mathrm{~g} / \mathrm{L}$ & $1.378 \pm 0.182$ & $-0.162 \pm 0.012$ \\
Complexing agent $25 \mathrm{~g} / \mathrm{L}$ & $1.878 \pm 0.224$ & $-0.156 \pm 0.018$ \\
Complexing agent $50 \mathrm{~g} / \mathrm{L}$ & $1.834 \pm 0.162$ & $-0.132 \pm 0.021$ \\
Complexing agent $75 \mathrm{~g} / \mathrm{L}$ & $1.821 \pm 0.150$ & $-0.145 \pm 0.008$ \\
Additive $0 \mathrm{~g} / \mathrm{L}$ & $1.121 \pm 0.098$ & $-0.163 \pm 0.011$ \\
Additive $50 \mathrm{~g} / \mathrm{L}$ & $1.137 \pm 0.252$ & $-0.137 \pm 0.022$ \\
Additive $100 \mathrm{~g} / \mathrm{L}$ & $1.154 \pm 0.331$ & $-0.133 \pm 0.027$ \\
Additive $150 \mathrm{~g} / \mathrm{L}$ & $1.124 \pm 0.363$ & $-0.151 \pm 0.031$ \\
Cerium nitrate $0 \mathrm{~g} / \mathrm{L}$ & $1.387 \pm 0.228$ & $-0.152 \pm 0.014$ \\
Cerium nitrate $0.5 \mathrm{~g} / \mathrm{L}$ & $1.421 \pm 0.311$ & $-0.141 \pm 0.017$ \\
Cerium nitrate $1.0 \mathrm{~g} / \mathrm{L}$ & $1.344 \pm 0.368$ & $-0.131 \pm 0.013$ \\
Cerium nitrate $1.5 \mathrm{~g} / \mathrm{L}$ & $1.302 \pm 0.116$ & $-0.135 \pm 0.025$ \\
Brush-plating times, 4 times & $1.345 \pm 0.166$ & $-0.156 \pm 0.009$ \\
Brush-plating times, 6 times & $1.341 \pm 0.337$ & $-0.155 \pm 0.014$ \\
Brush-plating times, 8 times & $1.442 \pm 0.342$ & $-0.131 \pm 0.019$ \\
Brush-plating times, 10 times & $1.445 \pm 0.352$ & $-0.127 \pm 0.024$ \\
Brush-plating times, 12 times & $1.443 \pm 0.271$ & $-0.126 \pm 0.025$ \\
\hline
\end{tabular}

Figure 6 shows alternating current impedance spectra of the copper sheet before and after brush plating in a $3.5 \%$ sodium chloride solution, and the equivalent electrical circuit of the system is also shown in Figure 6.

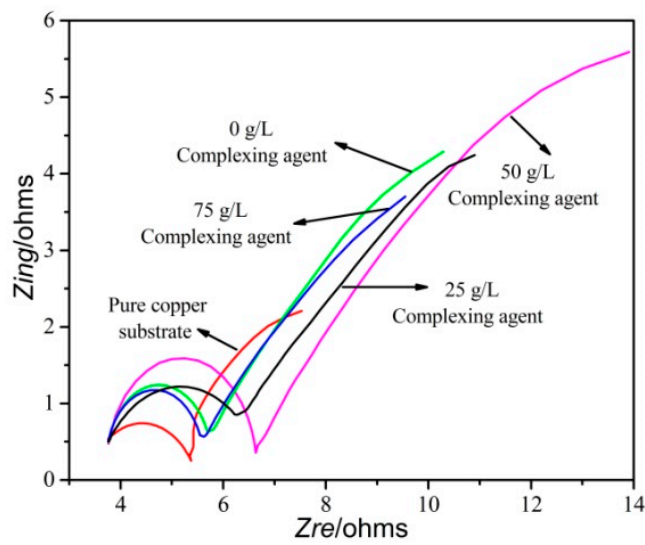

(a)

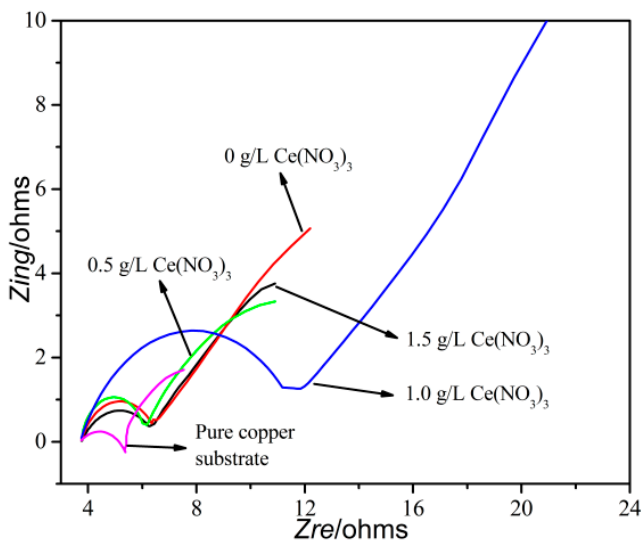

(b)

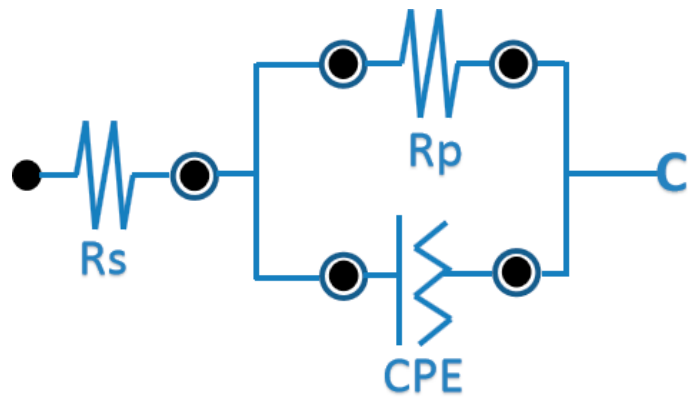

(c)

Figure 6. Impedance curve of the coating layer and equivalent electrical circuit.(a) different amounts of complexing agent content; (b) different amounts of cerium nitrate content; (c) equivalent electrical circuit.

It can be seen from the impedance map that the slope of the low-frequency region of all curves is about 1 , which indicates that the roughness of the silver coating in this experiment 
was not large or flat. It can be seen from the high-frequency region of the curve that the high-frequency capacitive arc resistance of the silver coating layer first increased and then decreased with the addition of a complexing agent or cerium nitrate, which indicated that the shielding ability of the coating first increased and then decreased. Additionally, the highest of the high-frequency capacitive arc resistance could be obtained with the dosage of a complexing agent or cerium nitrate were $50 \mathrm{~g} / \mathrm{L}$ and $1.0 \mathrm{~g} / \mathrm{L}$, which corresponded to the corrosion voltage of the coating layer.

As shown in Figures 7 and 8 and Table 3, the elemental composition and distribution of the coating were analyzed by a combination of EDS and element mapping. As can be seen from Figure 7 and Table 3, the surface of the coating contained $\mathrm{Ag}, \mathrm{Ce}, \mathrm{C}, \mathrm{Cu}$, and Au species elements, wherein the silver was the most abundant, reached $70.78 \%$ (weight), where the $\mathrm{C}$ probably attributed to the organic component that was added to the coating solution, the gold was due to the gold-spraying process before the test, and $\mathrm{Cu}$ was the matrix material. This indicated that the coating layer was based on silver.

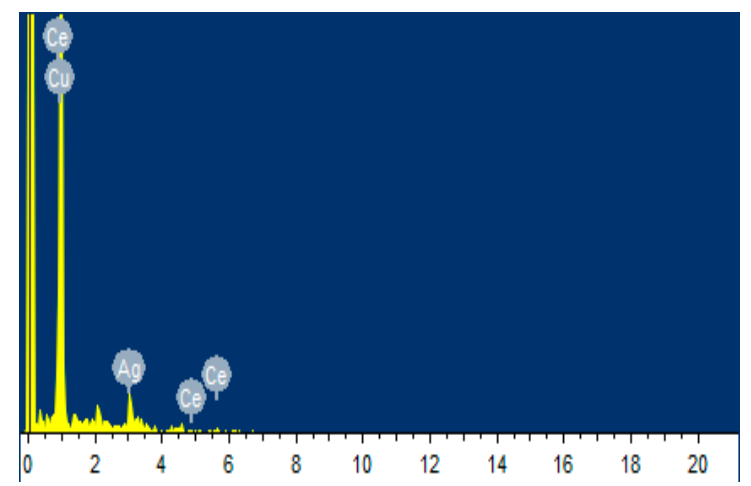

Figure 7. EDS of the silver-plated coating.

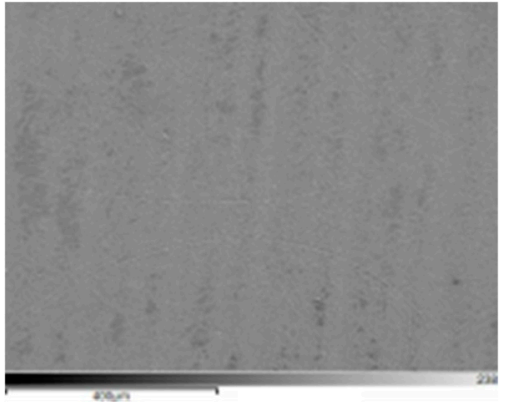

(a)

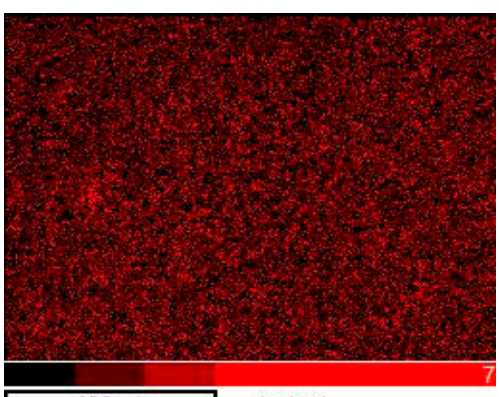

$400 \mu \mathrm{m}$
Ag La1

(c)

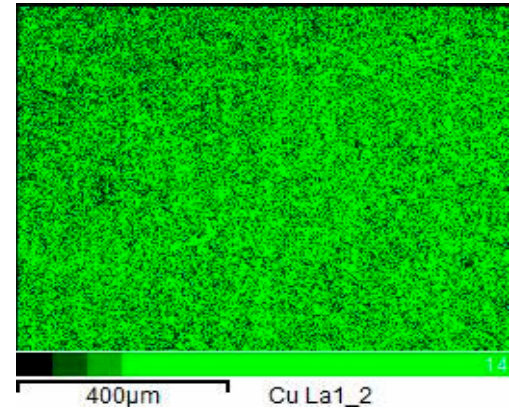

(b)

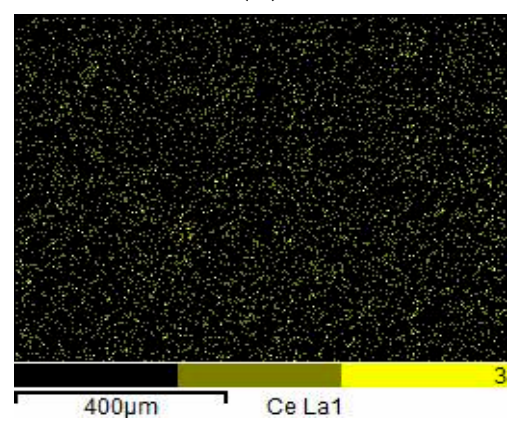

(d)

Figure 8. Elemental mapping of the silver-plated coatings.(a) electron image; (b) distribution of copper; (c) distribution of silver; (d) distribution of cerium. 
Table 3. The element content of the coating surface.

\begin{tabular}{ccccccc}
\hline Element & $\mathbf{C}$ & $\mathbf{C u}$ & Ag & Ce & Au & Total (\%) \\
\hline Weight (\%) & 1.57 & 1.08 & 70.78 & 0.35 & 26.22 & 100 \\
Atom (\%) & 13.91 & 1.81 & 69.92 & 0.2 & 14.16 & 100 \\
\hline
\end{tabular}

As evident from Figure 8, in which the elemental composition of the coating can be clearly seen, the silver element was uniformly coated on the surface of the copper layer substrate, and the small amount of cerium element was homogeneously dispersed in the silver coating layer, which indicated that the coating solution has great brush-plating property, stability, and homogeneity.

In order to further verify the silver crystal, the XRD results of the silver coating layer are shown in Figure 9. It was found that four intense diffraction peaks appeared at $(2 \theta)$ $38.07^{\circ}, 43.33^{\circ}, 50.37^{\circ}$ and $74.15^{\circ}$, respectively. The peak $\left(2 \theta=38.07^{\circ}\right)$ was attributed to the 200 plane of silver oxide [26], while the peaks $\left(2 \theta=43.33^{\circ}, 50.37^{\circ}\right.$, and $\left.74.15^{\circ}\right)$ corresponded to the copper's 111 plane, 200 plane, and 220 plane, respectively [27]. The result suggested that the silver coating layer was the main silver oxide.

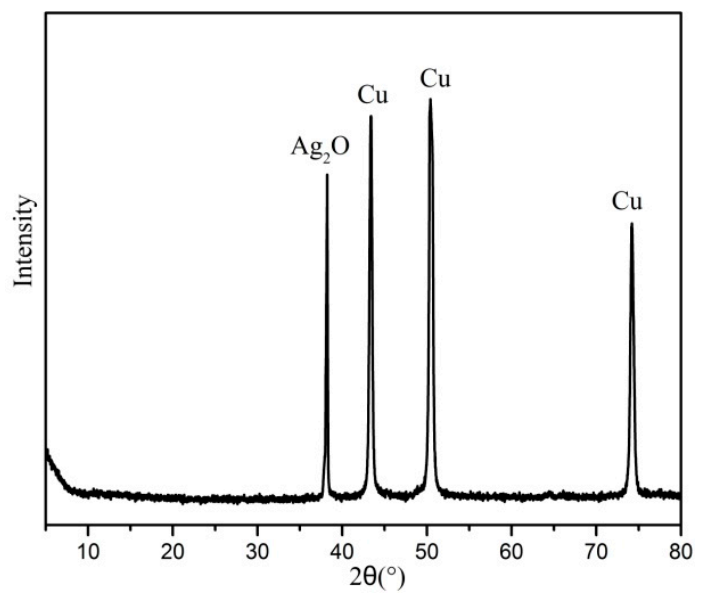

Figure 9. XRD of the silver coating layer.

\section{Application in the Power Industry}

Many disconnects in power equipment are corroded and oxidized after the equipment runs for a period of time outdoors, which causes abnormal heat and power failure. Therefore, these parts need to be repaired regularly. The portability of the accessory device determines the movability of the brush plating. Brush plating requires a set of matching brush-plating devices, such as those seen in Figure 10, which shows a brush-plating power supply and its corresponding talk device.

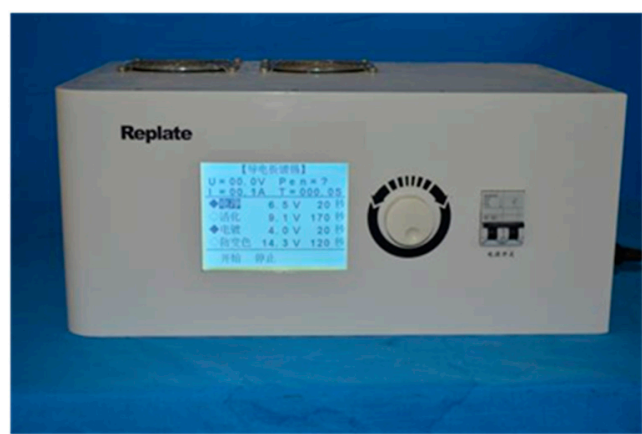

(a)

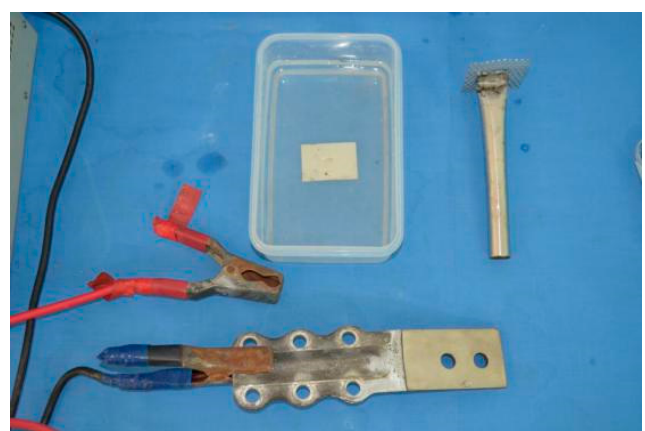

(b)

Figure 10. Brush-plating main tool. (a) power supply, (b) supporting device. 
The application was mainly to complete the silver layer on the copper substrate surface of the isolating switch. Figure 11 shows the comparison views of the isolating switch (GW4110), and the contact treated with and without coating. From the perspective of the effect of brush plating, it was relatively ideal, meeting the process requirements of field applications, especially the effect of reducing the contact resistance of the isolating switch.

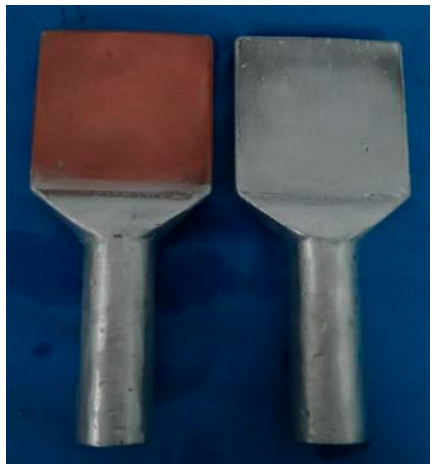

(a)

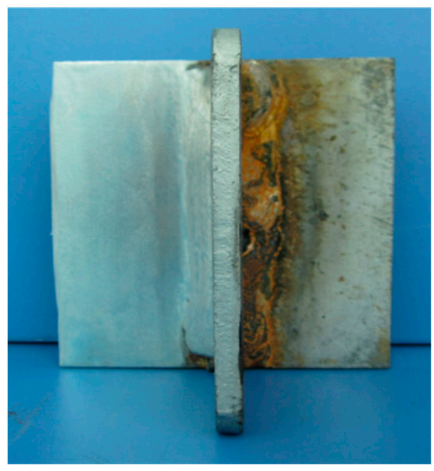

(b)

Figure 11. (a) Before and (b) after brush plating.

In order to analyze the repairing effect of the silver coating solution on the transformer's isolating switch, an infrared thermometer was applied to measure the temperature of the isolating switch treated with or without the silver coating solution. The results are shown in Figure 12. When the transformer ran at full load, the isolating switch without the silver coating had a high temperature of $100{ }^{\circ} \mathrm{C}$ during full load operation; however, a low temperature of $54{ }^{\circ} \mathrm{C}$ was obtained when the isolating switch was repaired with the silver coating solution. This result suggested that the coating solution system can effectively repair the transformer, reduce the contact resistance of the parts, and effectively solve the abnormal heating phenomenon during the normal operation of the equipment. Through the application example of the silver-plating process in the transformer, it was proved that the coating system is very applicable to power equipment, especially for large equipment outdoors.

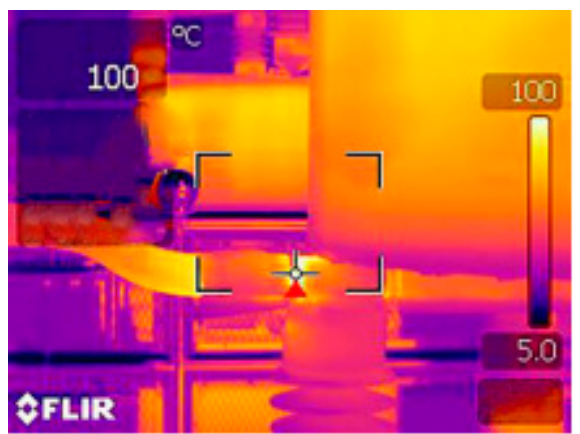

(a)

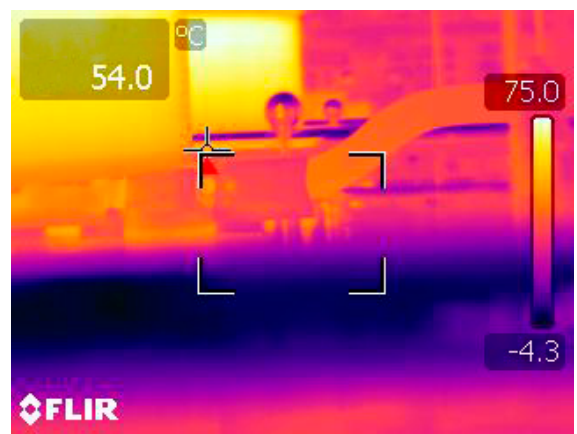

(b)

Figure 12. Infrared thermometry diagram of the operating equipment. (a) before brush plating, (b) after brush plating.

\section{Conclusions}

A bright and compact silver coating on a copper sheet was successfully prepared by a coating solution without cyanogen, and the coating solution was successfully applied in repairing the transformer's isolating switch. Results showed that good stability, dispersion, and corrosion resistance of the silver coating solution can result from its preparation with silver nitrate and sulfosalicylic acid. The incorporation of cerium nitrate obviously improved the physicochemical properties and corrosion resistance of the silver coating layer. 
When the dosages of silver nitrate, sulfosalicylic acid, additive, cerium nitrate, ammonium acetate, and polyethylene glycol 400 were 10,50,55,1,10, and $10 \mathrm{~g} / \mathrm{L}$, respectively, the best silver coating solution was obtained. Additionally, when the number of brush plating was eight, the silver coating layer based on the best silver coating solution could reach $30 \mu \mathrm{m}$, with good adhesion to the copper substrate, fully meeting the requirements for power equipment repair. This system showed great potential for repairing power equipment.

Author Contributions: Conceptualization, W.W. and W.L.; investigation C.H. and S.P.; data curation, Z.M. and J.L.; writing-original draft preparation, K.Z.; funding acquisition, C.Q. All authors have read and agreed to the published version of the manuscript.

Funding: Innovation and Entrepreneurship Training program for College students in Hubei Province, China (Grant No. 202110528011 and DC2021094).

Institutional Review Board Statement: Not applicable.

Informed Consent Statement: Not applicable.

Data Availability Statement: Not applicable.

Conflicts of Interest: The authors declare no conflict of interest.

\section{References}

1. Gao, X.; Yue, H.; Guo, E.; Zhang, H.; Lin, X.; Yao, L.; Wang, B. Mechanical properties and thermal conductivity of graphene reinforced copper matrix composites. Powder Technol. 2016, 301, 601-607. [CrossRef]

2. Yue, H.; Yao, L.; Gao, X.; Zhang, S.; Guo, E.; Zhang, H.; Lin, X.; Wang, B. Effect of ball-milling and graphene contents on the mechanical properties and fracture mechanisms of graphene nanosheets reinforced copper matrix composites. J. Alloy. Compd. 2017, 691, 755-762. [CrossRef]

3. Rohan, J.F.; O'Riordan, G.; Boardman, J. Selective electroless nickel deposition on copper as a final barrier/bonding layer material for microelectronics applications. Appl. Surf. Sci. 2002, 185, 289-297. [CrossRef]

4. Tseluikin, V.N.; Koreshkova, A.A. Electrochemical deposition and properties of composite coatings consisting of zinc and carbon nanotubes. Russ. J. Appl. Chem. 2015, 88, 272-274. [CrossRef]

5. Gyawali, G.; Joshi, B.; Tripathi, K.; Lee, S.W. Effect of Ultrasonic Nanocrystal Surface Modification on Properties of Electrodeposited Ni and Ni-SiC Composite Coatings. J. Mater. Eng. Perform. 2017, 26, 4462-4469. [CrossRef]

6. Lanzutti, A.; Lekka, M.; Leitenburg, C.; Fedrizzi, C. Effect of pulse current on wear behavior of Ni matrix micro-and nano-SiC composite coatings at room and elevated temperature. Tribol. Int. 2019, 132, 50-61. [CrossRef]

7. Li, J.; Fan, F.; Li, Q.; Du, F.; Yu, H. Influence of electric brush-plating voltage on hydrophobic behaviour of a cauliflower-like Ni coating surface. Micro Nano Lett. 2018, 13, 1159-1164. [CrossRef]

8. Hui, X.; Ivy, Q.; Horst, C.; Bob, C.; Viola, L. Behavior of palladium and its impact on intermetallic growth in palladium-coated Cu wire bonding. Acta Mater. 2013, 61, 79-88.

9. Güler, O.; Varol, T.; Alver, Ü.; Biyik, S. The wear and arc erosion behavior of novel copper based functionally graded electrical contact materials fabricated by hot pressing assisted electroless plating. Adv. Powder Technol. 2021, 32, 2873-2890. [CrossRef]

10. Montemor, M.; Ferreira, M. Analytical characterisation and corrosion behaviour of bisaminosilane coatings modified with carbon nanotubes activated with rare-earth salts applied on AZ31 Magnesium alloy. Surf. Coat. Technol. 2008, 202, 4766-4774. [CrossRef]

11. Zhenyu, Z.; Xinchun, L.; Baolei, H.; Jianbin, L. Rare earth effect on microstructure, mechanical and tribological properties of CoCrW coatings. Mater. Sci. Eng. A 2007, 444, 92-98.

12. Yaxu, J.; Bijian, D.; Daqing, F.; Baowen, Z. Phosphate Densification Technology and Properties of Rare Earth Conversion Films on Magnesium Alloy. Rare Met. Mater. Eng. 2017, 46, 3077-3080.

13. Song, G.; Cheng, N.; Zhang, J.; Huang, H.; Yuan, Y.; He, X.; Luo, Y.; Huang, K. Nanoscale Cerium Oxide: Synthesis, Biocatalytic Mechanism, and Applications. Catalysts 2021, 11, 1123. [CrossRef]

14. So, Y.M.; Leung, W.H. Recentadvances in the coordination chemistry of cerium(IV) complexes. Coord. Chem. Rev. 2017, 340, 172-197. [CrossRef]

15. Castano, C.; O’Keefe, M.J.; Fahrenholtz, W.G. Cerium-based oxide coatings. Curr. Opin. Solid State Mater. Sci. 2015, 19, 69-76. [CrossRef]

16. Xu, J.; Yu, H.; Zhang, C.; Guo, F.; Xie, J. Development of cerium-based catalysts for selective catalytic reduction of nitrogen oxides: A review. New J. Chem. 2019, 43, 3996-4007. [CrossRef]

17. Arshad, T.; Khan, S.A.; Faisal, M.; Shah, Z.; Akhtar, K.; Asiri, A.M.; Ismail, A.A.; Alhogbi, B.; Khan, S.B. Cerium based photocatalysts for the degradation of acridine orange in visible light. J. Mol. Liq. 2017, 241, 20-26. [CrossRef]

18. Tang, J.; Han, Z.; Zuo, Y.; Tang, Y. A corrosion resistant cerium oxide based coating on aluminum alloy 2024 prepared by brush plating. Appl. Surf. Sci. 2011, 257, 2806-2812. [CrossRef] 
19. Zou, Y.; Cai, C.; Xiang, C.; Huang, P.; Chu, H.; She, Z.; Xu, F.; Sun, L.; Kraatz, H.-B. Simple synthesis of core-shell structure of $\mathrm{Co}-\mathrm{Co}_{3} \mathrm{O}_{4} @$ carbon-nanotube-incorporated nitrogen-doped carbon for high-performance supercapacitor. Electrochim. Acta 2018, 261, 537-547. [CrossRef]

20. Bilgin, S.; Güler, O.; Alver, Ü.; Erdemir, F.; Aslan, M.; Çanakçı, A. Effect of TiN, TiAlCN, AlCrN, and AlTiN ceramic coatings on corrosion behavior of tungsten carbide tool. J. Aust. Ceram. Soc. 2021, 57, 263-273. [CrossRef]

21. Huifen, W.; Youliang, Z.; Jian, C.; Lee, S.; Kwong, W. Feature-based collaborative design. J. Mater. Processing Technol. 2003, 139, 613-618. [CrossRef]

22. Tingting, Z.; Kai, F.; Zhouguo, L.; Hiroyuki, K. Effects of rare earth elements on the microstructure and wear properties of TiB2 reinforced aluminum matrix composite coatings: Experiments and first principles calculations. Appl. Surf. Sci. 2020, 530, 147051.

23. Xiaolan, L.; Tao, Z.; Yawei, S.; Guozhe, M.; Fuhui, W. Effect of alternating voltage treatment on the microstructure and corrosion resistance of stannate conversion coating on AZ91D alloy. Corros. Sci. 2009, 51, 2685-2693.

24. Caiwen, O.; Wei, L.; Zailei, Z.; Ping, H. Effect of Electrodepositing Voltage on the Structural and in Vitro Corrosion Properties of CaP Coatings on ZK60 Magnesium Alloy. Int. J. Electrochem. Sci. 2013, 8, 11151-11160.

25. Taheri, P.; Dehghanian, C. Wear and corrosion properties of nanocrystalline coatings on stainless steel produced by plasma electrolytic nitrocarburizing. Int. J. Mater. Res. 2008, 99, 92-100. [CrossRef]

26. Xiaoyong, G.; Songyou, W.; Jing, L.; Yuxiang, Z.; Rongjun, Z.; Peng, Z.; Yuemei, Y.; Liangyao, C. Study of structure and optical properties of silver oxide films by ellipsometry, XRD and XPS methods. Thin Solid Film. 2004, 445-446, 438-442.

27. Junting, G.; Xu, Y. Study on the performance of nano-copper film deposited by magnetron sputtering. J. Funct. Mater. 2015, 46, 05123-05127. 